\title{
MONOCYTE-MEDIATED CYTOTOXICITY ON BLADDER CANCER CELLS IN VITRO AND ITS IMPLICATION IN THE TREATMENT OF BLADDER CANCER PATIENTS WITH BACILLUS CALMETTE-GUERIN
}

\author{
KAORU NAKAMURA \\ Department of Urology, School of Medicine, \\ Keio University, Tokyo, Japan
}

(Received for publication November 10, 1984)

\begin{abstract}
In order to clarify immunological role of bacillus Calmette-Guérin (BCG) in the treatment of bladder cancer, human monocyte-mediated cytotoxicity against human bladder cancer cell lines was determined. The tumor cell lines utilized were: a superficial bladder cancer derived cell line KU7 and an invasive bladder cancer derived cell line T24. Peripheral blood was obtained from 20 healthy volunteers (control group) and 10 patients with bladder cancer. Monocytes were separated from peripheral blood lymphocytes (PBL) by adherence on fetal bovine serum (FBS) coated plastic dishes. Cytolytic effects of monocytes were observed by determining ${ }^{3} \mathrm{H}$-thymidine ( $\left.{ }^{3} \mathrm{H}-\mathrm{TdR}\right)$ releasing assay and cytostatic effects were observed by determining ${ }^{3} \mathrm{H}-\mathrm{TdR}$ incorporation inhibition assay. The former assay had an inherent disadvantage due to the reutilization of ${ }^{3} \mathrm{H}-\mathrm{TdR}$. Therefore the latter assay was mainly used. The cytostatic effects against T24 in patients with bladder cancer were significantly lower as compared with that from control group $(45.6 \pm 6.6 \%$, $55.3 \pm 9.5 \%, \mathrm{p}<0.05)$. When KU7 was used as a target, cytostatic effects of monocytes from each source, as determined by the same method, were also observed, however no significant difference in the cytostatic effects was noted. Cytostatic effects against each target of monocytes from control group were then determined, after incubation of the monocytes with BCG of four different strength for varying length of time. The highest cytostatic effect (KU7: $68.4 \pm 9.8 \%$, T24: $75.1 \pm 10.6 \%$ ) was observed with $7.5 \times 10^{6}$ viable units of Tokyo 172 strain BCG with which monocytes from control group and KU7 were cultured for 24 hours. Cytostatic index (C.I.) as calculated by a formula [ 1-cpm (BCG treated monocyte + target) /cpm (untreated monocyte + target) $\times 100]$ were $57.5 \pm 6.2(\mathrm{KU} 7)$ and $42.7 \pm 11.8$ (T24) when monocytes from control group were used in comparison with $23.8 \pm 8.2$ (KU7) and $30.2 \pm 17.9$ (T24) when monocytes from bladder cancer were used. C.I. of monocytes from control group was significantly higher than that from patients with bladder eancer when KU7 was used as target $(p<0.001)$.
\end{abstract}

These results indicate a significant role of BCG as a nonspecific immuno- 
modulator and this in vitro study will provide a useful guideline to the treatment of bladder cancer.

\section{INTRODUCTION}

Since beneficial effects of BCG in cancer immunotherapy were introduced by Bast et al.,1 good results have been shown in the form of intravesical instillation of BCG for superficial bladder cancers.2-5 The mechanisms by which BCG generates its effects remain unclear, and extensive research, mainly utilizing animal models ${ }^{6,7}$ has been undertaken in this regard. However, because of different tumor antigenicity and subsequent alteration in host immune response, interpretation of the results obtained by animal models is often difficult fhen one persues clinical application of BCG. Therefore, experiments designed by using human effector and target cells can provide adequate informations to clarify the mechanisms.

In this study, human monocyte-mediated cytotoxicity for cell lines derived from human bladder cancer was determined. Effect of BCG upon cytostasis of cell lines was also analyzed.

\section{MATERIALS AND METHODS}

\section{Target cells}

KU7 derived from human bladder cancer (TCC grade 2) was established at the cell culture laboratory in the Department of Urology, School of Medicine, Keio University. ${ }^{8}$ T24 was established from human bladder cancer (TCC grade 3) by Bubenik et al. in 1973.9 These cells were maintained in Eagle's minimum essential medium (China Serum, Chiba, Japan) supplemented with $10 \%$ fetal bovine serum (FBS: Flow Lab., Virginia, USA) and cell lines were cultured in humidified atmosphere of $5 \% \mathrm{CO}_{2}, 95 \%$ air at $37^{\circ} \mathrm{C}$.

Stock cultures of a cell line were harvested and aliquots of either $5 \times 10^{5}$ cells were seeded in plastic culture flasks with $25 \mathrm{~cm}^{2}$ of growth area (Falcon 3013, Becton, Dickinson Lab., Oxnard, USA). At the time of that exponential phase of growth was achieved the medium was discarded and the cells in flasks dispersed into a single cell suspension with a mixture of $0.25 \%$ trypsin (Chiba Kessei) and $0.02 \%$ ethylene diamine tetra-acetic acid (EDTA: Wako Junyaku, Osaka) in phosphate-buffered saline (PBS). Each known aliquot was dispensed in fresh medium to get a cell medium suspension of $1 \times 10^{4}$ cells per ml. These cell medium suspensions were inoculated in 96-well MicroTest III Tissue Culture plates (Falcon 3072 Becton, Dickinson Lab, Oxnard, USA) by $1 \times 10^{3}$ cells for 
each well and were cultured for 24 hours.

\section{Monocyte preparation}

Peripheral blood lymphocytes (PBL) were donated from healthy adult volunteers (twenty males of age ranging from 20 to 30 year-old). Heparinized whole blood was centrifuged over Ficoll-Conray gradient and PBL were purified. PBL were washed twice with PBS and were resuspended in RPMI 1640 (GIBCO, Grand Island, New York) supplemented with $10 \%$ FBS at a concentration of $2 \times 10^{6}$ cells $/ \mathrm{ml}$ medium.

Adherent cells were obtained from PBL suspension by adherence on FBS coated plastic. ${ }^{10}$ Three $\mathrm{ml} \mathrm{FBS}$ heat-inactivated at $56^{\circ} \mathrm{C}$ for $30 \mathrm{~min}$ was incorporated into culture flasks (Falcon 3002) and then incubated in a refrigerator at $4^{\circ} \mathrm{C}$ overnight. The flasks were rinsed them three times with PBS. PBL of $1 \times 10^{7}$ cell in $5 \mathrm{ml}$ of RPMI 1640 containing $10 \%$ FBS were introduced into the serum-coated flasks. After incubation for $60 \mathrm{~min}$ at $37^{\circ} \mathrm{C}$, medium containing non-adherent cells was decanted and the flask was rinsed three times with warm RPMI $10 \%$ FBS to discard completely the nonadherent cells. Adherent cells were then removed from the dishes by incubation at $4^{\circ} \mathrm{C}$ with PBS containing $0.2 \%$ EDTA and 5\% FBS (EDTA-FBS) for $15 \mathrm{~min}$. Removal of cells still adherent to the dish at that time was achieved by jetting the medium to the cells using a pipette. Detached cells were more than $95 \%$ positive for $\alpha$-naphthyl acetateesterase ( $\alpha$-NAE) staining and more than $90 \%$ viable, as judged by trypan blue dye exclusion.

\section{Cytotoxicity assay (Fig. 1)}

1) Cytolytic assay ( ${ }^{3} \mathrm{H}-\mathrm{TdR}$ releasing assay)

Cytolytic effect of peripheral monocytes was determined by the isotope release from the ${ }^{3} \mathrm{H}-\mathrm{TdR}$ labeled target cells. ${ }^{11}$ An aliquot of $50 \mu \mathrm{l}$ of $20 \mu \mathrm{Ci} / \mathrm{ml}$ ${ }^{3} \mathrm{H}-\mathrm{TdR}$ (specific activity $20 \mathrm{Ci} / \mathrm{mM}$, New England Nuclear) in RPMI 1640 with $10 \%$ FBS was added to a well of target cells $\left(1 \times 10^{3}\right)$ and allowed to incubate for 24 hours. After the incubation of the target cells with ${ }^{3} \mathrm{H}-\mathrm{TdR}$, a well was washed with RPMI 1640 three times. Then the target cells were coincubated with monocytes for 12 to 48 hours and the kinetics of cytolytic effect was determined. Monocyte effector cells were added at the appropriated concentrations to obtain final effector cell : target cell ratio ( $\mathrm{E} / \mathrm{T}$ ratio) of $10: 1$ to $100: 1$.

After 12 to 48 hours incubation, residual incorporated radioactivity of target cells was determined by harvesting cultures onto scintillation grade glass fiber (Titertek, Flow Lab., U.K.) using a multiple cell harvester Mark II (Labo Mash, Labo Science Co.) and determining counts per minute (cpm) by liquid scintilla- 


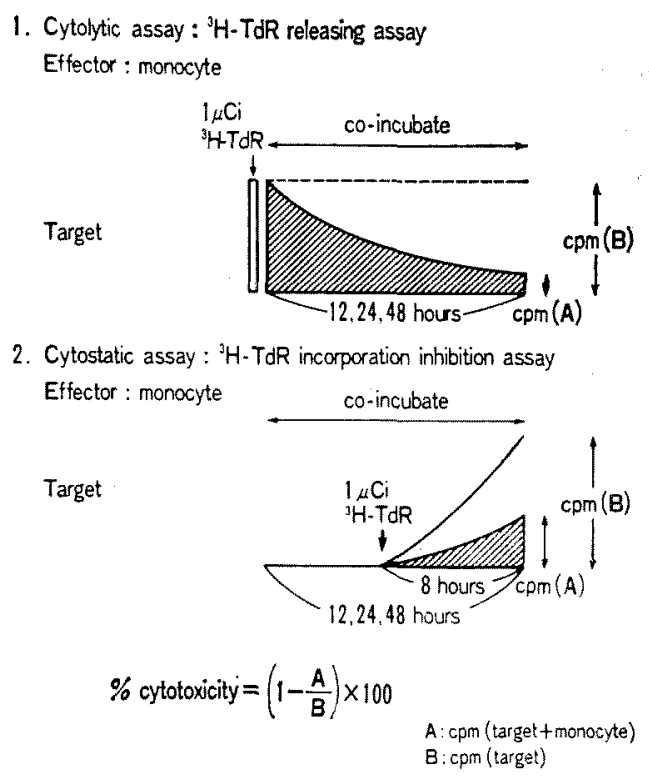

Fig. 1 Cytotoxicity assay.

tion counting. The percentage of cytolytic effect was determined by the following formula :

$$
\begin{aligned}
& \% \text { cytotoxicity }= \\
& \frac{(\text { cpm of target cells })-(\mathrm{cpm} \text { of target cells and effector cells })}{(\mathrm{cpm} \text { of target cells alone })} \times 100
\end{aligned}
$$

All experiments were done triplicately.

2) Cytostatic assay ( ${ }^{3} \mathrm{H}-\mathrm{TdR}$ incorporation inhibition assay $)^{12}$

Various numbers of effector cells (from $1 \times 10^{4}$ to $1 \times 10^{5} / \mathrm{ml}$ ) were added to triplicate wells containing target cells $\left(1 \times 10^{3}\right)$ to achieve $E / T$ ratio of $10: 1,20: 1$, $50: 1$ and $100: 1$. The cultures were incubated for from 12 to 48 hours at $37^{\circ} \mathrm{C}$ in a $5 \% \mathrm{CO} 2$ atmosphere, and $1 \mu \mathrm{Ci}$ of ${ }^{3} \mathrm{H}$-TdR was added to each well for the final 8 hours of culture. Incorporated radioactivity was determined by the same as cytolytic assay. The percentage of cytostatic effect was determined by the same formulas as above mentioned.

4. Activation of monocyte-mediated cytotoxicity by BCG

BCG (Tokyo 172 strain, Japan BCG Co., Tokyo, Lot 2193M) in concentration of $1 \mathrm{mg} /$ vial was used. Each vial was labeled as containing approximately $1.5 \times 10^{7}$ 
viable units of $\mathrm{BCG} / \mathrm{mg}$. Monocytes at concentration of $1 \times 10^{6}$ cells $/ \mathrm{ml}$ RPMI 1640 with $10 \%$ FBS were coincubated with $\mathrm{BCG}$ at various concentration of $1.5 \times 10^{5}$ to $1.5 \times 10^{7}$ viable units $/ \mathrm{ml}$ at $37^{\circ} \mathrm{C}$ in a $5 \% \quad \mathrm{CO}_{2}$ atmosphere. The duration of incubation time varied from 8 to 72 hours. After the coincubation with BCG, monocytes were washed three times by RPMI 1640 and were resuspended at concentration of $1 \times 10^{6} / \mathrm{ml}$ RPMI 1640 with $10 \%$ FBS. The cytostatic assay of BCG treated monocytes was done and the enhancement of cytostatic effect was determined by the following formula: ${ }^{13}$

Cytostatic Index (C.I.) $=$

$\left\{\frac{\begin{array}{c}\mathrm{cpm} \text { (untreated monocyte }+ \text { target) } \\ -\operatorname{cpm}(\text { BCG treated monocyte }+ \text { target })\end{array} \times 100}{\text { cpm (untreated monocyte }+ \text { target) }}\right\}$

5. Monocytes from patients with bladder cancer

Heparinized whole blood was obtained from ten patients with bladder cancer treatment. The pathological diagnosis of those patients were: TCC grade 1 ( 3 cases), grade 2 ( 1 case), grade 3 (5 cases) and squamous cell carcinoma ( 1 case). The monocytes were prepared by the same procedure as normal volunteers. Cytostatic effect and cytostatic index were determined by the above mentioned method at the adequate incubation time $\mathrm{E} / \mathrm{T}$ ratio and doses of $\mathrm{BCG}$.

\section{RESULTS}

1. Purification of monocyte

PBL were obtained from $40 \mathrm{ml}$ of whole blood of 20 normal volunteers. The fraction of monocytes purified by means of FBS-coated plastic adherent method was $4.9 \pm 2.4 \%$ of PBL. The adherent cells were more than $95 \%$ positive for $a-\mathrm{NAE}$ staining and more than $90 \%$ viable, as judged by trypan blue.

2. Incorporation of ${ }^{3} \mathrm{H}-\mathrm{TdR}$ into target cells and effector cells (Table 1)

Labeling of KU7, T24, and monocytes with $1 \mu \mathrm{Ci}{ }^{3} \mathrm{H}-\mathrm{TdR}$ for the last 8 hours of cultivation for 24 hours in wells were shown in Table 1 . Rate of incorporation of ${ }^{3} \mathrm{H}-\mathrm{TdR}$ into both untreated and BCG-treated monocytes was 0.8 to $2.7 \%$ of that of KU7 and T24. Therefore it could be negligible of incorporation of ${ }^{3} \mathrm{H}-\mathrm{TdR}$ into effector cells when the cytostatic assay was performed.

3. Kinetics of the cytolytic and cytostatic effect of monocyte (Fig. 2, 3)

Kinetics of cytolytic effect of monocyte to KU7 showed significant increase from 12 to 48 hours $(p<0.01)$ in $E / T$ ratio of $20: 1$ and $50: 1$, whereas kinetics of cytostatic effect showed significant increased from 12 to 24 hours $(p<0.001)$ 
Table 1

Incorporation of ${ }^{3} \mathrm{H}-\mathrm{TdR} \mathbf{1}$

\begin{tabular}{lcc}
\hline \multicolumn{1}{c}{ Cells } & No. of cells & cpm \\
\hline KU7 & $1 \times 10^{3}$ & $3068.0 \pm 178$ \\
T24 & $1 \times 10^{8}$ & $1396.0 \pm 119$ \\
Untreated Monocyte & $2 \times 10^{4}$ & $25.3 \pm 2.9$ \\
BCG treated Monocyte & $2 \times 10^{4}$ & $37.7 \pm 4.1$ \\
\hline
\end{tabular}

1) Labeling of cells with $1 \mu \mathrm{Ci}{ }^{3} \mathrm{H}-\mathrm{TdR}$ for the last 8 hours of cultivation.

2) Coincubation of monocyte with $7.5 \times 10^{6}$ viable units of BCG for 24 hours.

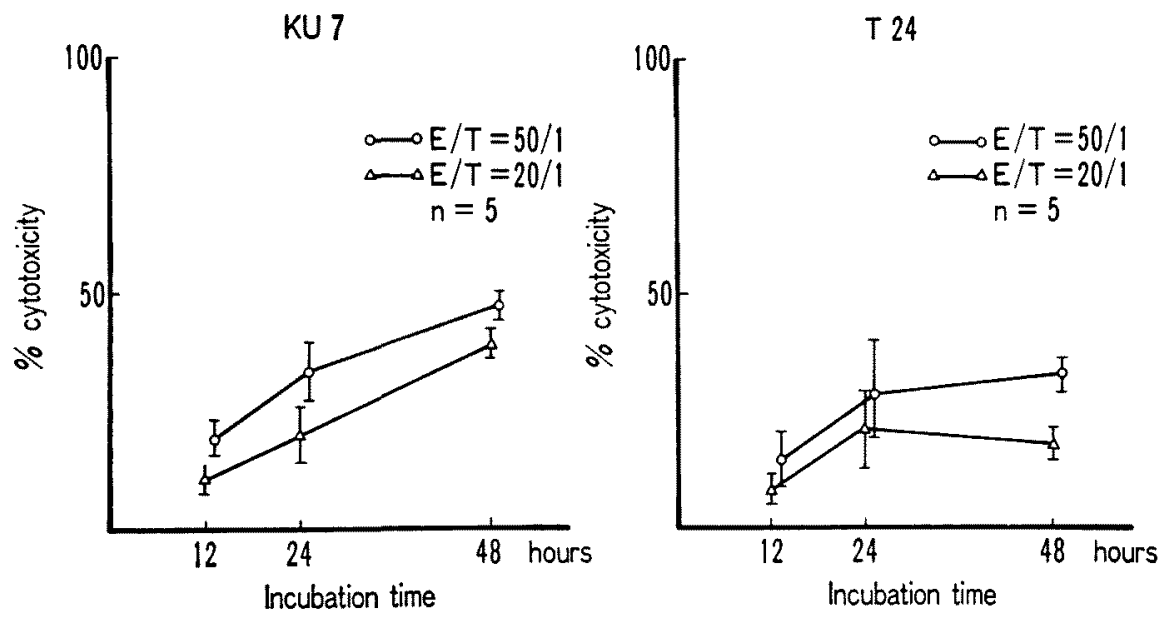

Fig. 2 Kinetics of cytolytic effect of monocyte on KU7 and T24.
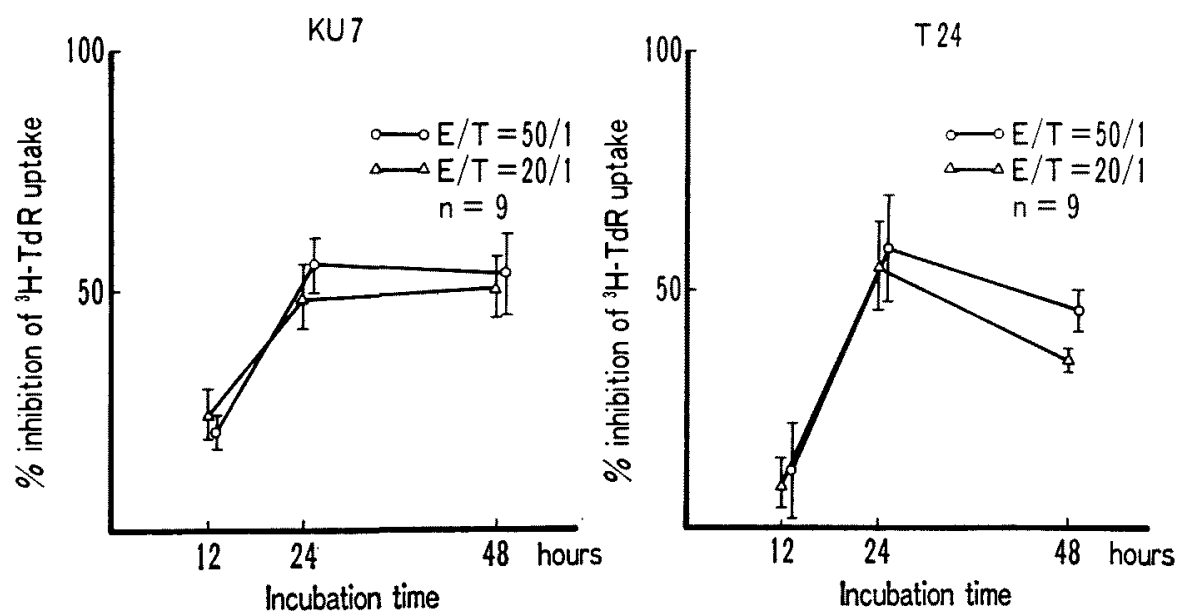

Fig. 3 Kinetics of cytostatic effect of monocyte on KU7 and T24. 
and became plateau at 48 hours. Kinetics of cytolytic effect of monocyte to T24 showed significant increase from 12 to 24 hours $(\mathrm{p}<0.05)$ and became plateau at 48 hours. Kinetics of cytostatic effect showed significant peak at 24 hours $(\mathrm{p}<0.001)$. In preliminary study, the rate of spontaneous release of ${ }^{3} \mathrm{H}-\mathrm{TdR}$ incorporate into KU7 and T24 was less than 15\% within 48 hours, however it was more than $30 \%$ as long as 72 hours. Therefore the long-term assay more than 72 hours was not performed. Based on the above result, 24 hours assay was used in comparison of KU7 to T24.

4. Effect of varying $\mathrm{E} / \mathrm{T}$ ratios on monocyte-mediated cytotoxicity (Fig. 4, 5)

Assays were performed for 24 hours based on the result of kinetics. Relation between the cytotoxicity and $\mathrm{E} / \mathrm{T}$ ratio revealed almost the same pattern in KU7 and T24. Cytotoxicity increeased significantly with increasing $\mathrm{E} / \mathrm{T}$ ratios from $10 / 1$ to $50 / 1$ in both assays.

5. Monocyte-mediated cytostatic effect in patients with bladder cancer (Table 2)

Cytostatic effect of monocytes from ten patients with bladder cancer was determined at $\mathrm{E} / \mathrm{T}$ ratio of $20 / 1$ and coincubation with targets for 24 hours. Because the number of monocytes obtained from patients with bladder cancer limited, cytolytic effect could not be assayed simultaneously. As shown in Table 2, there was significant decrease in \%cytotoxicity of patients with bladder cancer using T24 as targets $(p<0.05)$, however no significant difference exists using

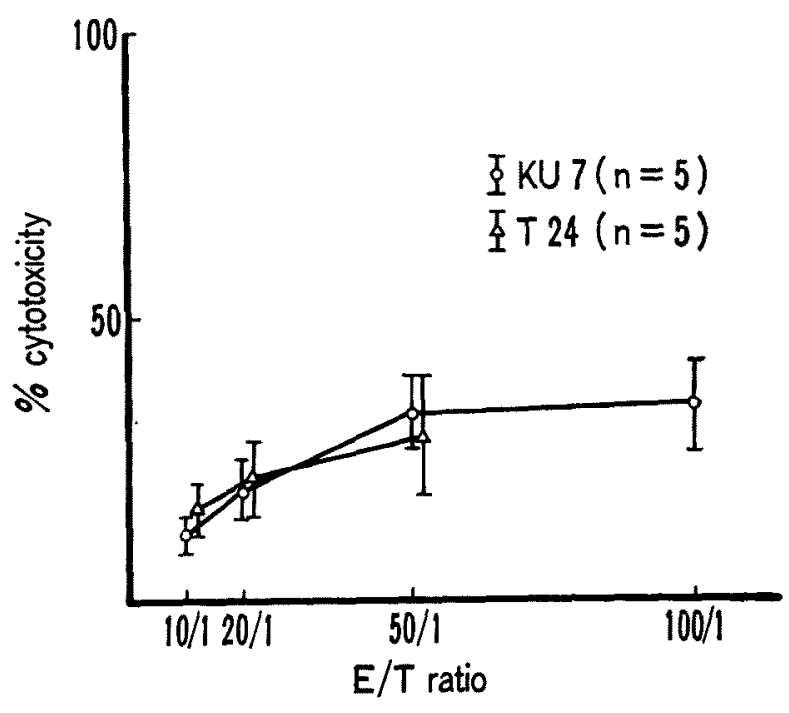

Incubation time was 24 hrs.
Fig. 4 Influence of varying $\mathrm{E} / \mathrm{T}$ ratios on cytolytic effect against KU7 and T24. 


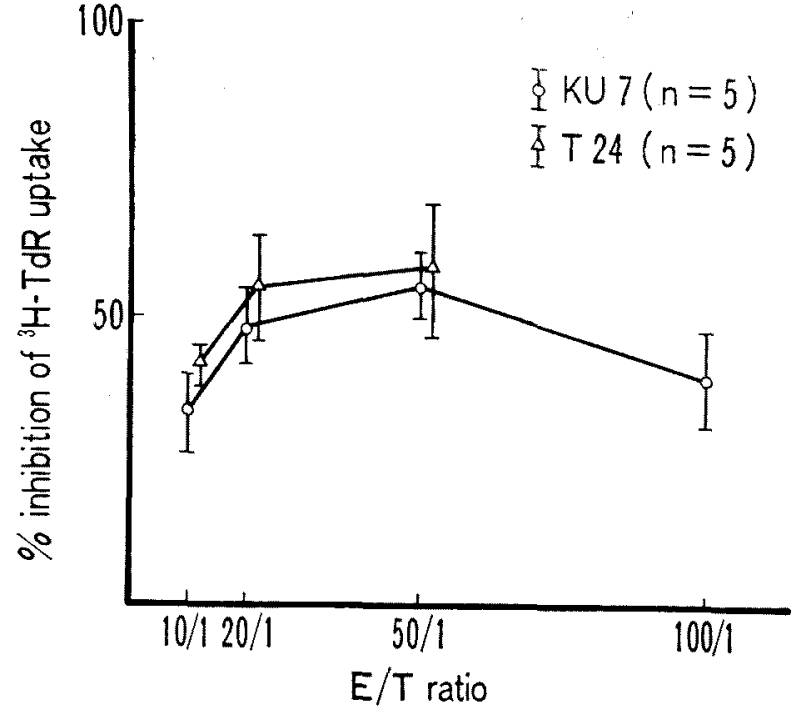

Incubation time was $24 \mathrm{hrs}$
Fig. 5. Influence of varying $\mathrm{E} / \mathrm{T}$ ratios on cytostatic effect against KU7 and T24.

Table 2

$\%$ inhibitions of ${ }^{3} \mathrm{H}-\mathrm{TdR}$ uptake of monocytes in normal volunteers and patients with bladder cancer

\begin{tabular}{ccc}
\hline & \multicolumn{2}{c}{$\%$ inhibition of ${ }^{\mathrm{s}} \mathrm{H}-\mathrm{TdR}$} \\
\cline { 2 - 3 } Target & $\begin{array}{c}\text { Normal volunteers } \\
(\mathrm{n}=9)\end{array}$ & $\begin{array}{c}\text { Pts. bladder ca. } \\
(\mathrm{n}=10)\end{array}$ \\
\hline $\mathrm{KU} 7$ & $48.5 \pm 6.6$ & $47.5 \pm 12.6$ \\
$\mathrm{~T} 24$ & $55.3 \pm 9.5^{2)}$ & $45.6 \pm 5.6^{2)}$ \\
\hline
\end{tabular}

1) $24 \mathrm{hr}$ cytostatic assay, $\mathrm{E} / \mathrm{T}=20 / 1$

2) Significant $(\mathrm{P}<0.05)$

KU7 as targets.

6. Effect of BCG on cytostatic effect of monocyte (Fig. 6, 7)

1) Doses of BCG and C.I.

The assays were performed at $\mathrm{E} / \mathrm{T}$ ratio of $20 / 1$. One $\times 10^{6}$ of freshly isolated monocytes were coincubated with $1.5 \times 10^{5}$ to $1.5 \times 10^{7}$ viable units of BCG for 24 hours. The peak of C.I. was $57.5 \pm 6.2$ (KU7) and $42.7 \pm 11.0$ (T24), which was observed when the $7.5 \times 10^{6}$ viable units of BCG was coincubated with 


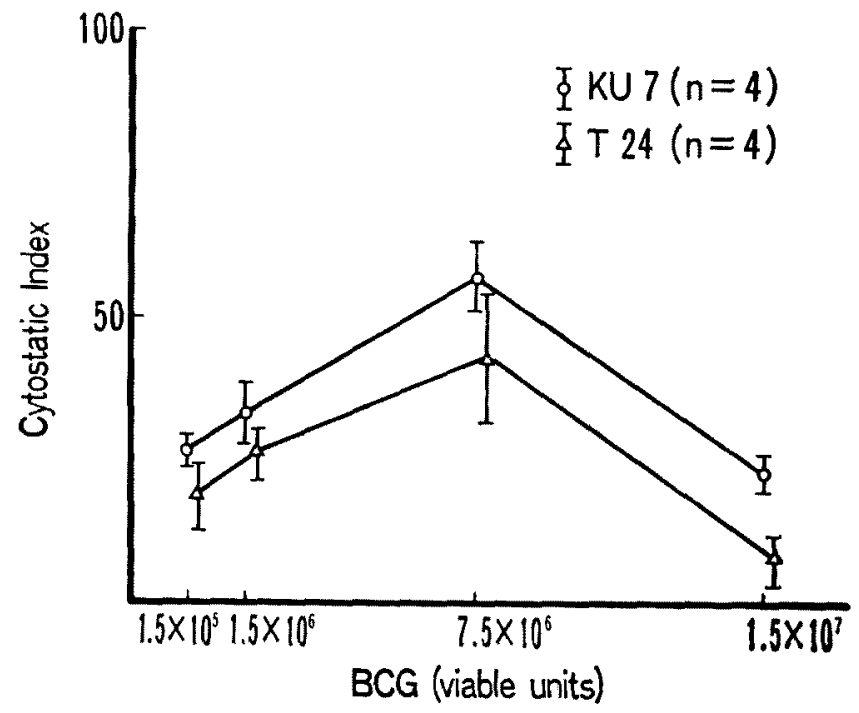

Fig. 6 Effect of varying doses of BCG on cytostatic index.

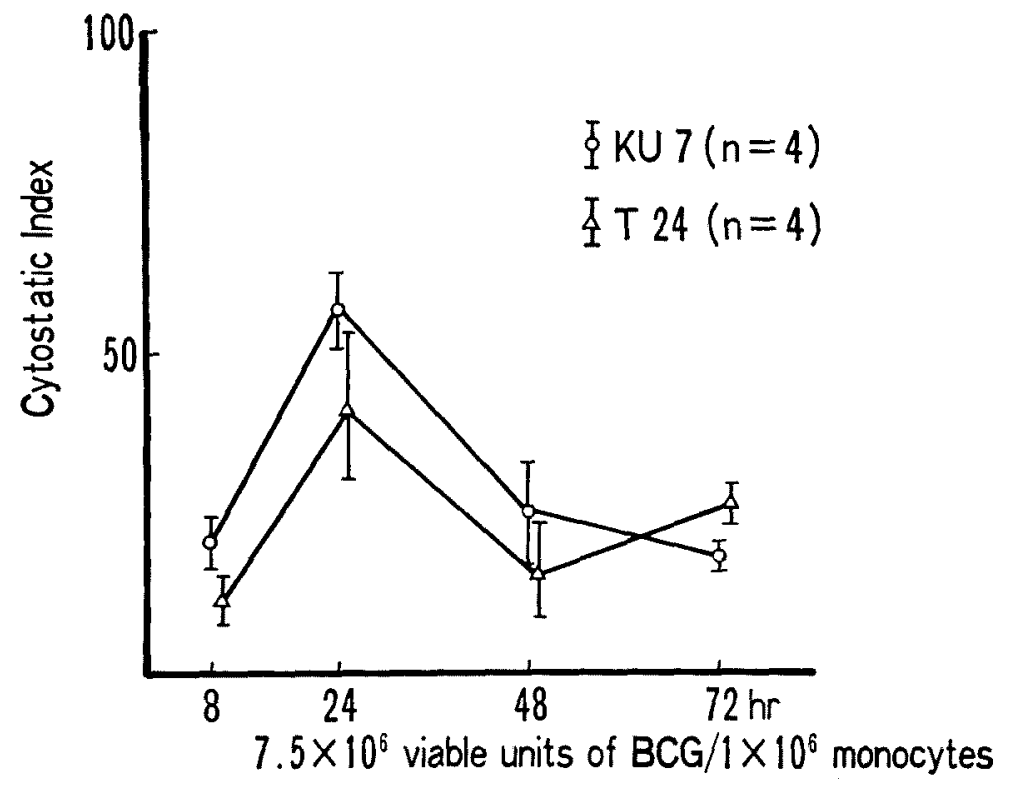

Fig. 7 Effect of varying incubation times of monocyte with BCG on cytostatic index. 
$1 \times 10^{6}$ of monocytes. There was significant decrease in C.I. when $1.5 \times 10^{7}$ viable units of BCG was used.

2) Effect of varying incubation times of BCG on C.I.

$7.5 \times 10^{6}$ viable units of BCG was coincubated with $1 \times 10^{6}$ of monocytes for varying incubation times. The peak of C.I. was determined at 24 hours of incubation. Maximum C.I. was $57.5 \pm 6.2$ (KU7) and $42.7 \pm 11.8$ (T24).

7. Cytostatic Index of monocytes from patients with bladder cancer (Fig. 8, Table 3)

Monocytes from five patients with bladder cancer were coincubated with

Table 3

Cytostatic index ${ }^{1}$ in normal volunteers and patients with bladder cancer

\begin{tabular}{ccc}
\hline & \multicolumn{2}{c}{ Cytostatic Index } \\
\cline { 2 - 3 } Target & $\begin{array}{c}\text { Normal volunteers } \\
(\mathrm{n}=9)\end{array}$ & $\begin{array}{c}\text { Pts. bladder ca. } \\
(\mathrm{n}=10)\end{array}$ \\
\hline KU 7 & $57.5 \pm 6.2^{2)}$ & $23.8 \pm 8.2^{2)}$ \\
T 24 & $42.7 \pm 11.8$ & $30.2 \pm 17.9$ \\
\hline
\end{tabular}

1) $1 \times 10^{6}$ monocytes coincubated with $7.5 \times 10^{6}$ viable units of $B C G$.

2) Significant $(P<0.001)$

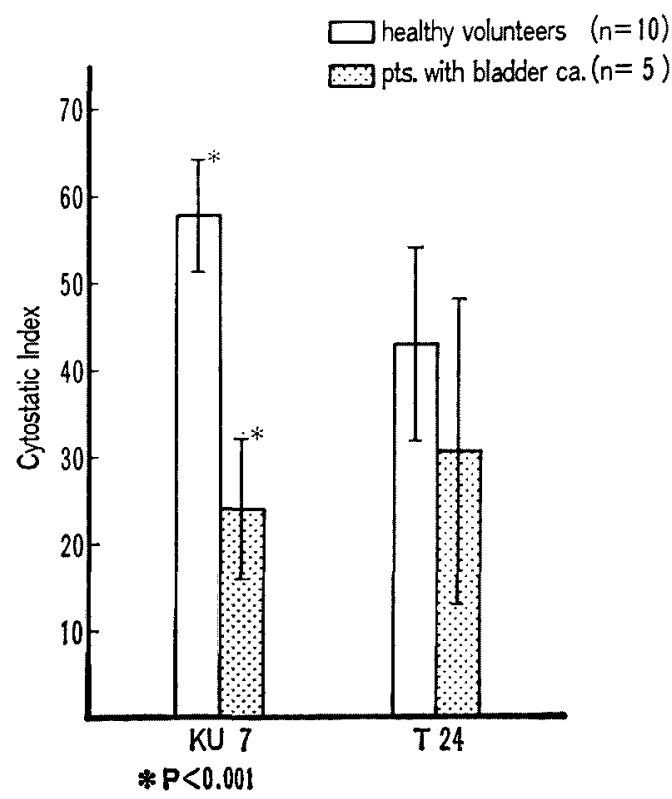

Fig. 8 Cytostatic index of healthy volunteers and patients with bladder cancer. 
$7.5 \times 10^{6}$ viable units of BCG for 24 hours and then were washed three time with RPMI 1640. When KU7 was used as targets, C.I. of healthy volunteers was $57.5 \pm 6.2$ and that of patients with bladder cancer was $23.8 \pm 8.2$. The latter was significantly lower than the former $(p<0.001)$. On the other hand, when T24 was used as targets, there was no significant difference between C.I. of both groups.

\section{DISCUSSION}

Several assay techniques are available for determination of monocyte-mediated cytotoxicity against tumor target and these include cytolytic assay using ${ }^{3} \mathrm{H}-\mathrm{TdR}$ or ${ }^{51} \mathrm{Cr}$-labeled target cell and cytostatic assay using ${ }^{3} \mathrm{H}-\mathrm{TdR}$ or ${ }^{125 \mathrm{I}-}$ iododeoxyuridine ( $\left.{ }^{125} \mathrm{I}-\mathrm{UdR}\right)$ incorporation into target cells. ${ }^{11,14}$ With ${ }^{51} \mathrm{Cr}$-labeled target cells, long incubation could result in high spontaneous release, thus limiting the target spectrum that can be tested. Therefore, as a cytolytic assay which requires more than 24 hours incubation, an assay with ${ }^{51} \mathrm{Cr}$-labeled target is not optimal. ${ }^{3} \mathrm{H}-\mathrm{TdR}$ was used in cytolytic assay for prelabeling targets in this study, since spontaneous release has been shown in the present study to be less than $15 \%$ even in 48 hours incubation. Regarding cytostatic assay, ${ }^{3} \mathrm{H}-\mathrm{TdR}$ incorcopration inhibition assay has been shown to well correlate with cell count method with Giemsa staining. ${ }^{11,12}$ The good correlation was also shown by our preliminary study in which cytostatic effeces of monocytes of healthy volunteers against KU7 and T24 were analyzed by two different methods mentioned above. Target cytolysis, when compared to target cytostasis, seems to represent a better parameter to determine susceptibility of the target to undergo damage by a given agent to be examined. However, an inherent disadvantage to use cytolysis assay is that released radioactive marker can be reutilized and causes a decrease in true cytolytic activity. Jagarlamoody et al. ${ }^{15}$ have reported that ${ }^{3} \mathrm{H}-\mathrm{TdR}$ DNA label can be reutilized during cytolytic assay, thereby lowering estimates of cell death. Therefore cytostatic assay was used to determine BCG-induced activation of monocyte-mediated cytotoxicity in the present study.

The results presented here show that monocytes of healthy volunteers have higher cytostatic effects than monocytes of patients with bladder cancer upon cell lines derived from human bladder cancer in vitro. Also shown is the highest cytostasis obtained after 24 hours incubation of monocytes of healthy volunteers with BCG of $7.5 \times 10^{6}$ viable units and that cytostatic effects of monocytes either from healthy volunteers or patients with bladder cancer is significantly enhanced with BCG.

In the present study, cell lines derived from human bladder cancer were used. Their antigenic differences have been recently reported, ${ }^{8}$ utilizing newly produced monoclonal antibody (Mab) to established cell lines (KU1, KU7). Therefore, sig- 
nificance of the observed antigenic difference of targets deserved consideration if one wishes to draw any conclusion regarding specificity of monocyte-mediated cytotoxicity.

It is conceivable that small percentage of natural killer (NK) cells contaminate adherent cell population ${ }^{16}$ while adherent cell population is being separated from PBL, thereby effecting upon cytotoxicity of monocytes thus obtained. Eggens ${ }^{1 i}$ has recently reported that contaminating $\mathrm{NK}$ cells in adherent monocyte population detach during the first 24 hours of in vitro culture. Since monocytes were incubated for 24 hours and thoroughly washed thereafter in the present study, majority of adherent cells are most likely to represent monocytes. However, a possibility that a very small amount of contaminating cells may contain sufficient NK cells to contribute to observed effects on tumor cells in cytotoxicity assays. $^{18}$ In this regard, anti-NK monoclonal antibody expressed of a high proportion of NK cells, to deplete purified adherent cell population on NK cells, can be used for further purification of monocytes, as reported by Kleinerman et al. ${ }^{19}$

Eventhough increased cytolytic and cytostatic effect were observed by increasing $\mathrm{E} / \mathrm{T}$ ratio, a rate of the increase remained within a narrow range. Furthermore, smaller volumes of blood suit in vitro cytostatic assay, therefore $\mathrm{E} / \mathrm{T}$ ratio was adjusted to $20: 1$. When $\mathrm{E} / \mathrm{T}$ ratio was adjusted $100: 1$, cytostatic effect of monocytes of healthy volunteers on KU7 was decreased. The cause of decreased cytostatic effects cannot be explained by the data obtained.

Mantovani et al.11 have reported on determination of cytostasis of circulatory normal human monocytes upon various murine and human tumor target cell lines by inhibition of ${ }^{125} \mathrm{I}-\mathrm{UdR}$ uptake. They have observed different susceptibility of the various target cell lines to cytolytic activity, whereas comparable levels of cytostasis with the various target cells were noted. Gerrard et al. ${ }^{20}$ have reported that normal human peripheral blood monocytes are cytotoxic selectively for several adherent tumor cells including a human bladder cancer cell lines (T24), a human melanoma line (LR) and an SV40-transformed fibroblast cell lines (SV40W138) when determined by ${ }^{3} \mathrm{H}-\mathrm{TdR}$ release assay, with no contribution of lymphokines to exert the cytotoxic effect and that monocytes from cancer patients are normal in their tumoricidal activity but monocyte-mediated cytotoxicity is inhibited by plasma from some cancer patients.

However, Jerrells et al. ${ }^{21}$ have reported that peripheral blood mononuclear cells of most normal adults and patients with breast and lung cancer are capable of inhibiting ${ }^{3} \mathrm{H}-\mathrm{T} d \mathrm{R}$ uptake by human lymphoid cell lines (F-265) in a growth inhibition assay and that at $\mathrm{E} / \mathrm{T}$ ratios between $5: 1$ and $20: 1$, lung cancer patients and breast cancer patients, when compared to normal individual, show significantly higher inhibition of ${ }^{3} \mathrm{H}-\mathrm{TdR}$ uptake by the human lymphoid cell line (F-265). No explanation is given in their report regarding reasons for the observed difference other than the presence of the active tumor. 
In the present study, monocytes from healthy volunteers exhibited similar cytostatic effect on two target cell lines. Since the two target cells are shown to have different antigenic characteristics, cytostatic effects mediated by monocytes of healthy volunteers are most likely to be non-specific. Cytostatic effect on T24 of monocytes from patients with bladder cancer was significantly lower as compared with that from control group, whereas no significant difference was noted with KU7. Camerons et al.22 have reported conversion of non-cytotoxic macrophage to cytotoxic macrophages when indomethacin (prostaglandin synthetase inhibitor) is added to the culture medium of macrophage during cytotoxicity assay of cancer patients' macrophages to allogenic target cell or autologous target cells. Since quantitative analysis of prostaglandin was not obtained in the present study, lower cytotoxic effect of monocytes from patients with bladder cancer cannot be attributed to prostaglandin. The result obtained, on the other hand, may simply indicate the cytotoxicity of monocytes, either from normal volunteers or cancer patients, is also nonspecifically directed toward tumor cells.

In the present study, monocytes, either from normal volunteers or cancer patients, coincubated with BCG prior to cytotoxic assay showed enhanced effects on KU7 and T24. Cameron et al. ${ }^{23}$ have reported that bacterial lipopolysaccharide (LPS) stimulated normal human monocytes to kill cells (a human breast cancer derived cell lines, SK-BR-3). Although cytolytic assay was used in their study, the maximum cytotoxicity was observed after 8 to 24 hours of incubation with LPS and the maximum dose of LPS to enhance the cytotoxicity was a dose of 10 to $25 \mu \mathrm{g} / \mathrm{ml}$ with declining enhancement with doses in excess of $25 \mu \mathrm{g} / \mathrm{ml}$. Dosedependent increase in cytotoxicity in the present study is similar to their results. In addition, Unsgaard ${ }^{2+}$ has shown that $1 \times 10^{6}$ viable units of BCG stimulated maximumly JNA synthesis of $1 \times 10^{6}$ lymphocytes. The dose of BCG which caused the maximum stimulation is in accord with the result shown in the present study.

Despite overall BCG-enhanced cytostatic effects of monocytes either from healthy volunteers or patients with bladder cancer, a discrepancy was noted regarding the degree of enhancement by monocytes from different sources. Since the mechanisms responsible for known depressed monocytes function in cancer patients are not fully understood, ${ }^{25}$ the discrepancy cannot be explained by the data shown in the present study.

\section{SUMMARY}

Cytotoxicity of monocytes from peripheral blood against two different cell lines KU7 and T24 derived from human bladder cancer was determined.

1. The optimal incubation time was 24 hours and $\mathrm{E} / \mathrm{T}$ ratio was $20: 1$ to $50: 1$ 
for monocyte-mediated assay.

2. Cytolytic assay, determined by ${ }^{3} \mathrm{H}-\mathrm{TdR}$ releasing, had an inherent disadvantage due to the reutilization of ${ }^{3} \mathrm{H}-\mathrm{TdR}$.

3. Cytostatic assay, determined by ${ }^{3} \mathrm{H}-\mathrm{TdR}$ incorporation inhibition was well correlated with cell count method.

4. Monocytes from patients with bladder cancer showed significantly lower cytostatic effects against T24 not KU7 than monocytes from healthy volunteers, however no such a difference was noted when $\mathrm{KU}-7$ was used.

5. The optimal condition for BCG-induced enhancement of \%inhibition of ${ }^{3} \mathrm{H}$ TdR uptake was determined.

6. Monocytes from patients with bladder cancer showed lesser enhancement by BCG than that from healthy volunteers when KU7 was used as target.

7. The results indicate a significant role of BCG as a non-specific immunomodulator.

\section{ACKNOWLEDGEMENT}

The author is deeply indebted to Professor Hiroshi Tazaki, Chairman of the Department of Urology, School of Medicine, Keio University, for his advice and encouragement throughout the study. Author's deep appreciation is also to Dr. Seido Jitsukawa, Dr. Nobuhiro Deguchi, Dr. Shiro Baba, Dr. Masaru Murai and Dr. Masaaki Nakazono from Keio University.

This study was presented at the forty-third Annual Meeting of Japanese Cancer Society on October 7th, 1984, Fukuoka. This study was partly supported by Grant-in-Aid for Scientific Research (A: 59440068) from the Ministry of Education, Science and Culture.

\section{REFERENCES}

1. Bast, R. J. Jr., Zbar, B., Borsos, T. et al.: BCG and Cancer. New Engl. J. Med. 290: 1413-1420, 1974

2. Morales, A., Eidinger, D. and Bruce, A.W.: Intracavitary bacillus CalmetterGuérin in the treatment of superficial bladder tumors. J. Urol. 116: 180-183, 1976

3. Lamm, D. L., Thor, D. E., Winters, W. D. et al.: BCG immunotherapy of bladder cancer: inhibition of tumor recurrence and associated immune responses. Cancer 48: 82-88, 1981

4. Herr, H. W., Pinsky, C. M., Whitomore, W. F. et al.: Effect of intravesical bacillus Calmette-Guérin (BCG) on carcinoma in situ of the bladder. Cancer 51: 1323-1326, 1983

5. Morales, A.: Long-term results and complications of intracavitary bacillus Calmett-Guérin therapy for bladder cancer. J. Urol. 132: 457-459, 1984

6. Shapiro, A., Ratliff, T. L., Oakley, D. M. et al.: Reduction of bladder tumor growth in mice treated with intravesical bacillus Galmette-Guérin and its correlation with bacillus Calmette-Guérin viability and natural killer cell. Cancer Res. 43: 1611-1615, 1983

7. Pang, A.S. and Moroles, A.: BCG induced murine peritoneal exudate cells: cytotoxic activity against a syngeneic bladder tumor cell line. J. Urol. 127: 1225-1229, 1982 
8. Sasaki, M.: Production and characterization of monoclonal antibodies to the established human bladder cancer cell lines. Keio J. Med. 33: 39-56, 1984

9. Bubenik, J, M., Baresova, M., Viklicky, V. et al.: Established cell line of urinary bladder carcinoma (T24) coneaining tumor specific antigen. Int. J. Cancer 11: 765-773, 1973

10. Kumagai, K., Itoh, K., Hinuma, S. et al.: Pretreatment of plastic petri dishes with fetal calf serum. A simple method for macrophage isolation. J. Immuno. Methods 29: 17-25, 1979

11. Mantovani, A., Jerrells, T. R., Dean, J.H. et al.: Cytolytic and cytostatic activity of tumor cells of circulating human monocytes. Int. J. Cancer 23: 18-27, 1979

12. Rinehart, J. J., Lange, P., Gormus, B. J. et al.: Human monocyte-induced tumor cell cytotoxicity. Blood 52: 211-220, 1978

13. Hammerstrom, J., Unsgaard, G. and Lamvik, J.: Activation of human monocytes by mediators from lymphocytes stimulated with corynebacterium parvum. Acta Path. Microbil. Scand. Sect. C. 87: 167-175, 1979

14. Norman, S. J. and Cornelius, J.: Cytokinetics of macrophage-mediated cytotoxicity. Cancer Res. 44: 2313-2319, 1984

15. Jagarlamoody, S. M., Aust, J. C., Tew, R. H. et al.: In vitro detection of cytotoxic cellular immunity against tumor-specific antigens by a radioisotopic technique. Pro. Natl. Acad. Sci. USA 68: 1346-1350, 1971

16. Freundlich, B. G., Trinchieri, B., Perussia, B. et al.: Cytotoxic effector cells from human peripheral blood adherent cells. Fed. Proc. 42: 955, 1983

17. Eggen, B. M.: Cytotoxicity of temporarily adherent human mononuclear blood cells. I. Cytotoxic abilities of cells after detachment from culture cells. Acta Pathol. Microbiol. Immunol. Scand. 90: 123-128, 1982

18. Frendlich, B., Trinchieri, G., Perussic, B. et al.: The cytotoxic effector cells in preparations of adherent mononuclear cells from human peripheral blood. J. Immunol. 132: 1225-1260, 1984

19. Kleinerman, E.S. and Herberman, R. B.: Tumoricidal activity of human monocytes: evidence for cytolytic function distinct from that of NK cells. J. Immunol. 133: 4-6, 1984

20. Gerrard, T. L., Terz, J. J. and Kaplan, A. M.: Cytotoxicity to tumor cells of monocyte from normal individuals and cancer patients. Int. J. Cancer 26: 585-593, 1980

21. Jerrells, T. R., Dean, J.H., Richardson, G. et al.: Increased monocyte-mediated cytostasis of lymphoid cell lines in breast and lung cancer patients. Int. J. Cancer 23: 768-776, 1979

22. Cameron, D. J., Rittenbury, M. and Majeski, J.: Ability of cancer patients' macrophages to kill autologous tumor targets. Cancer 53: 2053-2057, 1984

23. Cameron, D.J. and Churchill, W.H.: Cytotoxicity of human macrophages for tumor cells: enhancement by bacterial lipopolysaccharides (LPS). J. Immunol. 124: 708-712, 1980

24. Unsgaard, G., Hammerstrom, J. and Lamvik, J.: Cytostatic effect on tumor cells induced in human monocytes by medicators from BCG-stimulated lymphocytes and MLC. Acta Path. Microbiol. Scand. Sect. C 87: 159-166, 1979

25. Kleinerman, E. S., Zwelling, L. A., Howser, D.: Defective monocyte killing in patients with malignancies and restoration of function during chemotherapy. Lancet: Nov. 22, 1102-1105, 1980 